\title{
TRAVEL BEHAVIOUR IN SAUDI ARABIA AND THE ROLE OF SOCIAL FACTORS
}

\author{
Attiyah Al-Atawi ${ }^{1}$, Wafaa Saleh ${ }^{2}$ \\ ${ }^{1}$ Department of Civil Engineering, University of Tabuk, Saudi Arabia \\ ${ }^{2}$ Transport Research Institute, Edinburgh Napier University, United Kingdom
}

Submitted 11 November 2013; accepted 31 March 2014; first published online 9 May 2014

\begin{abstract}
Travel behaviour research indicates that travel decisions are usually influenced by accessibility as well as characteristics of the transport systems. Factors such as travel times, travel costs, waiting times, walking times have the most significant contributions in mode choice and travel decisions. In the case of developing countries however, the most influencing factors for travel behaviour and decisions are the social factors. This is very important for transport modellers and decision makers to realise in order to achieve appropriate design and implementations of various transport policies. The influence of social and economic factors on travel behaviour are discussed and investigated in this paper. In Saudi Arabia, a randomly selected sample of 1220 households was interviewed in the Tabuk city of the Saudi Arabia and data on their socio-economic and trip-making behaviour was obtained. The relative impact of socioeconomic variables on household travel behaviour was discussed and discrete choice models were calibrated. These types of studies can be useful in the development of plans, programs and policies for the improvement of transportation systems in urban areas of the Saudi Arabia and other similar countries in the region. The findings show that the social factors have the most important impact on travel behaviour in Saudi Arabia.
\end{abstract}

Keywords: travel behaviour; social factors; Tabuk city; Saudi Arabia; sustainable travel behaviour.

Reference to this paper should be made as follows: Al-Atawi, A.; Saleh, W. 2014. Travel behaviour in Saudi Arabia and the role of social factors, Transport 29(3): 269-277. http://dx.doi.org/10.3846/16484142.2014.913199

\section{Introduction}

Unsustainable travel behaviour and global greenhouse gas emissions are growing and due to the perceived indispensable nature of personal travel, shifts to more sustainable modes remain a challenge (Howarth, Polyviou 2012). When transport policies are sought, the three main components of sustainability (economic, social and environmental) are often challenged. For example, while auto mobility supports sustained local economic growth, it also raises problems include congestion, delays, safety, air pollution and visual intrusion. These problems have been dealt with traditionally using a 'predict and provide' approach (i.e. predict demand and provide supply). More recently, a shift to travel behaviour and travel demand management approaches have been adopted (Saleh, Sammer 2009).

The issue of traveller behaviour and sustainability have been extensively researched and analysed, but mainly in Western countries (Crane 1998; Cervero 2002; Srinivasan 2002). On the other hand, in a developing country like India, Srinivasan and Rogers (2005) analysed the differences in travel behaviour due to differences in accessibility to employment and services between the two settlement locations and finally concluded that those differences in accessibility were strongly affecting the travel behaviour. They suggested location of employment in the planning of new housing for low-income households. Limtanakool et al. (2006) reported land use attributes and travel time considerations as important factors in explaining the variation in mode choice for medium- and longer-distance travel when controlling for the socioeconomic characteristics of travellers.

In another study in Tehran done by Shokoohi et al. (2012) examined the influence of the socio-economic factors on Children's School Travel. They added to the literature by showing result that living within walking distance from school $(500 \mathrm{~m})$ may not guarantee walking as the children's mode of transportation to and from school, especially if on their own. Their research confirms that traffic safety is definitely a barrier to children's

Corresponding author: Wafaa Saleh

E-mail: w.saleh@napier.ac.uk 
walking to and from school on their own; an issue which should be considered by any programme that targets the changing travel patterns. Their study also provided an analytical framework to examine how traffic safety and cultural norms may relate to children's travel behaviour, and investigated impacts that other factors have on the perception of safety. They found that parental concerns about traffic safety factors in a neighbourhood are changing according to their average monthly income and access to car; parents with higher average monthly income have more transportation options available to send their children to school which reduce the likelihood of their children walking to schools.

Other researchers investigated the role of social factors on travel behaviour and decisions in other countries - see for example, Anable and Gatersleben (2005), Babatunde (2012), Badoe and Miller (1998).

Yang et al. (2013) discussed the combined choice of residential location, travel mode, and departure time, using a number of traditional and more advanced discrete choice models, Cross-Nested Logit (CNL) model in Beijing and explained that for long-distance commuting, it is difficult to decrease car travels even if additional charges are imposed on car users. The effect on choice probability by variations in travel time of other travel mode can be considered as negligible for alternatives within $5 \mathrm{~km}$ commuting distance, and this effect are greatest for alternatives between 10 and $20 \mathrm{~km}$ commuting distance affect transport demand management and residence planning.

In Saudi Arabia, Koushki (1988) constructed a profile of the socio-economic and travel behaviour of individual households in Riyadh, and compared their traits with those of households in the United States. A systematic random sample of 2250 households was homeinterviewed and data on their socio-economic and tripmaking behaviour obtained. The relative impact of the socio-economic variables on household travel behaviour was discussed and compared between household traits in Riyadh and in the U.S. The results were useful in the development of plans, programs and policies for the improvement of transportation systems in urban areas of the Saudi Arabia.

Paul and Rimmawi (1992) survey conducted investigation at the Al-Sawdah resort, Saudi Arabia by collecting information on the nationalities of visitors, their duration of stay, and the catchments area of the resort. Their results indicated that the majority of the visitors came from Asir and neighbouring provinces. Visitors from distant places usually stayed longer, compared to those travelling shorter distances. Additionally, the number of previous trips was found to be inversely related to the duration of stay. Their finding helped in promoting domestic tourism. Almunajjed (1997) researched women in Saudi Arabia Further work which investigated travel behaviour and attitudes in Saudi Arabia include Abdalla (2002), Mohammadian (2005), Abou-Zeid and Ben-Akiva (2011), Adetunji (2012), AlMohamed (2008).
Mohareb (2010) carried out an analysis of the different factors, which effect land use in Arab cities and the modes of transportation used to access was affected by type of land use. He put forward the argument that throughout history Arab cities have developed in a completely different manner when compared to those of Western cities. Prior to the colonisation of these cities they were allowed to develop where daily socio-cultural activities were located within walking distance of residential zones. However due to the influx of Western ethos into these cities, there has been a change in the methods adopted in urban development and over time this has led to a zoning of activities that depends heavily on vehicles for transportation (Mohareb 2010). This change in general design of cities along with the rapid expansion of Gulf cities has led to an increased need for motorised transportation for residents to move between their required zones. It should be noted however that Saudi cities were not subject to colonisations.

Tabuk city has typical travel characteristics of a medium size Saudi city. It should be noted here that for cultural reasons women don't drive in the Saudi Arabia. Moreover, workplaces as well as schools for men are separate than work places for women.

The paper investigates and models travel behaviour and attitudes of households of Tabuk city in Saudi Arabia and evidence of responses to sustainable travel behaviour. This current investigation is very important in order to identify the particular factors and issues which controls travel behaviour and choices. A wide range of data has been collected and analysed in this study, and a set of logit based models have been explored from car user and informal car sharer. The analysis includes two parts: Firstly, a general analysis and investigation of the results and the findings. This analysis includes analysis of mode of travel, family structure and work sectors. Secondly, discrete choice analysis and models have been calibrated and discussed for the main two modes of travel; cars and car sharing.

\section{Study Area and Data Collection}

Tabuk city is the capital city of the Tabuk region of Saudi Arabia located in the North West of the country. The city has a population of over 440000 residents and houses the largest air force base in the country. An overview the country as a whole with the Tabuk region and city present in the North West of the country is provided in Fig. 1 with a more detailed map of the Tabuk region as a whole being presented in Fig. 2 giving a more accurate location Tabuk city within this region.

A large data set has been collected and analysed in this study using a questionnaire. The questionnaire as a whole comprised of five separate sections. The first section of the questionnaire analysed the current travel patterns of the respondents in which they were asked to identify the mode of transportation, which they use to reach their place of work along with some characteristics of this mode such as the travel time, travel costs. In the second section of the questionnaire the respond- 


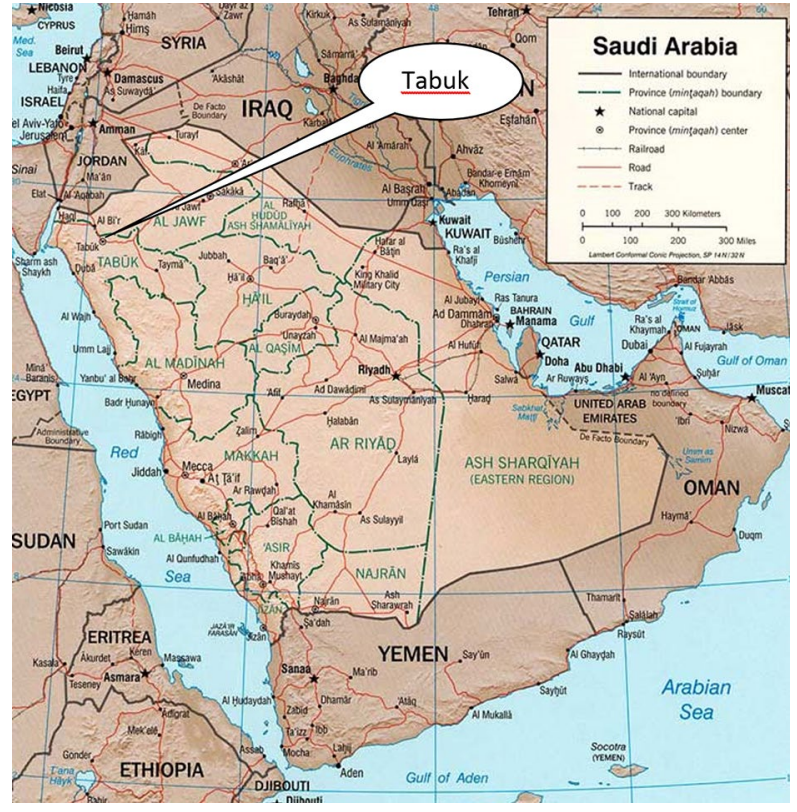

Fig. 1. Location of Tabuk region

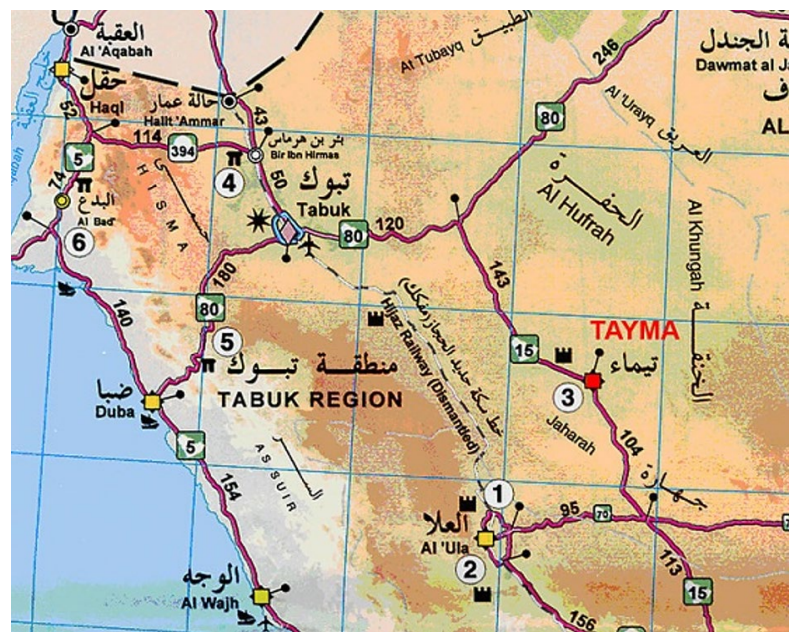

Fig. 2. Positioning of Tabuk city within the region ents were asked to provide their opinions on alternative modes of transport and provide a rating of these modes in relation to a number of different criteria such as comfort, reliability cost travel time etc. This was aimed at determining how willing individuals to change their mode of transportation and what it is that would instigate the decision to change.

The questionnaire went on to gather information, in the third section on the times of departures and arrival and their flexibility in changing these times. This aimed to establish a trend of travel patterns within the city in order to identify the peak travel times. The fourth section investigated respondents' attitudes to a number of a number of traffic and transport policies and finally data was collected on socio economic characteristics of the individuals and the households. In total, 1226 surveys were distributed throughout the Tabuk city, overall 516 completed surveys were returned which gave an overall response rate of $42.0 \%$ for the study as a whole. Questionnaires distributed in different sectors in order to cover all workplaces in Tabuk. This includes: Health services (Hospitals, Health care centres, Military's hospital), Educational services (Boys' Schools, Girls' schools, University of Tabuk, Prince Fahad bin Sultan University), Military sector (King Faisal Airbase, King Abdulaziz Military City), Security Sector (Police, Traffic Department, Border Guard, Civil Defence), Private sector (Banks, Consultants, Saudi Electricity Company, Saudi Telecom Company), Tabuk Municipality and Water Authority.

\section{General Discussions of the Findings}

\subsection{Mode of Travel to Work}

Fig. 3 shows the patterns of travellers and their regularity of using different modes to travel to work. From the data collected from the surveys (Al-Atawi, Saleh 2013), it was found a total of $55.7 \%$ (287) of respondents indicating that they regularly drive to work, with 43 individuals indicated that they sometimes or seldom drove to work, while a further $14.5 \%$ indicated that they never drove to work.

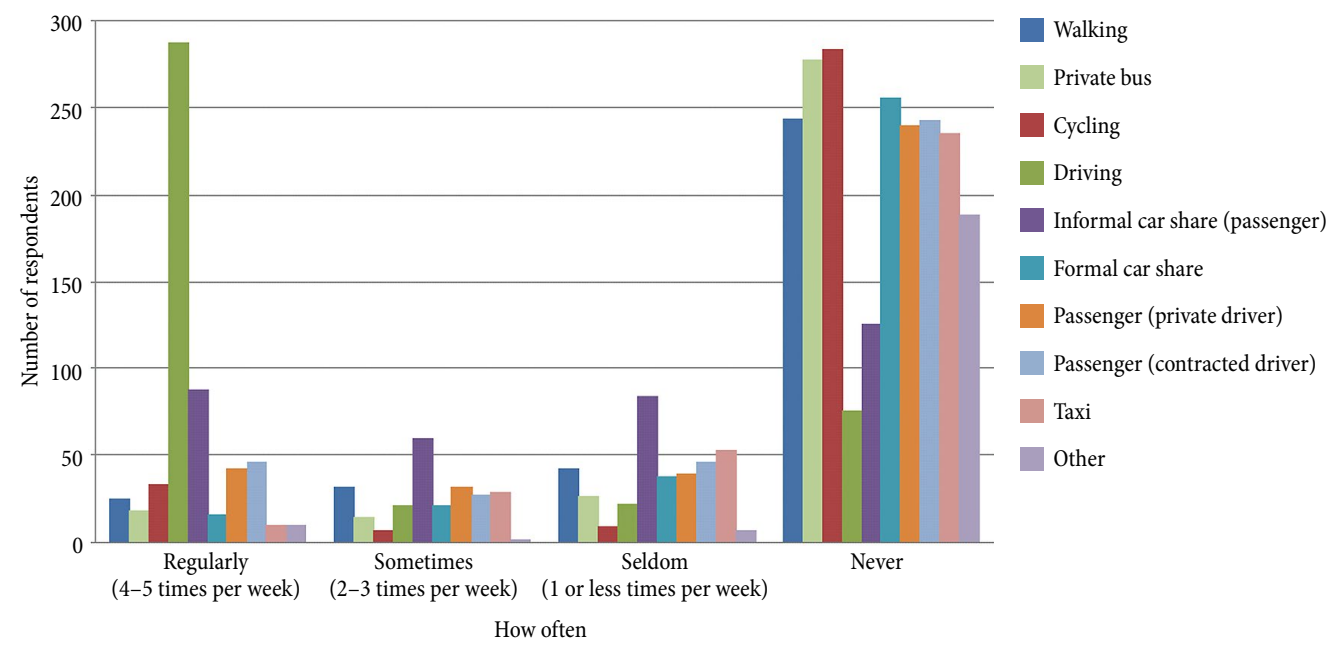

Fig. 3. Patterns of travellers and their regularity of using different modes to travel to work 
The second most common mode of transportation utilised was through informal car share schemes with $17 \%$ (88) of the respondents indicated that they utilised this method while formally organised car sharing schemes accounted for a further $3 \%$ (16) of regular work journeys. With regards to commuter journeys using a private vehicle in which the individual was a passenger with some forms of professional driver in place it was seen that a total of $42(8.1 \%)$ individuals utilised a private driver on a regular basis while 46 (8.93\%) individuals employed a contracted driver regularly. Private bus and cycling accounted for $20 \%$ (107) journeys combined, with only 3.5 and $6.4 \%$ of respondents indicating that they utilised each mode on a regular basis. $54 \%$ of respondents indicated that they never used private buses with a further $55 \%$ of individuals never choosing to cycle to their destination. Within the private bus option it was seen that 2.7 and $5 \%$ of respondents chose to sometimes and seldom utilise this mode, while these frequency of use accounted for 1.4 and $1.7 \%$ of journeys through cycling.

When the use of a private driver is further examined it was seen that 32 (6.2\%) and 39 (7.57\%) individuals used these services on a less regular basis under the sometimes and seldom options respectively. The use of taxis as a mode of transportation was seen to increase as the frequency of use decreased with 29 (5.6\%) individuals indicating that they would sometimes use this means of transportation with this level rising to $53(10.3 \%)$ on a seldom basis. A total of 235 (45.6\%) individuals indicated that they never use taxis as a means of transportation to their place of work. On the other hand, a total of $25(4.85 \%)$ individuals indicated that they regularly walked to their place of employment with these levels rising to $32(6.21 \%)$ and $42(8.16 \%)$ respectively for the sometimes and seldom choices. A total of 244 or $47 \%$ or respondents indicated that they never walked to their place of work while a further 10 (2\%) individuals indicated that they took a taxi to work on a regular basis.
A summary of this data in relation to mode choice are presented in Fig. 3.

Interestingly when further analysis of this information are carried out, the results show that most people do use other modes than the private car, even though these other modes can involves the car as seen in Table 1 . Results show that there are at least $31 \%$ of travellers use other modes than drive a car. It also seem that the main factor to the selection of transport mode is the social role of each member of the family, as mainly the people who drive are the heads of families while wives and daughters do not have access to driving in the Saudi Arabia. Further discussions of this are found in (AlAtawi, Saleh 2013).

\subsection{Family Structure}

As part of this study, respondents were requested to provide information in relation to the structure of their family unit. Individuals were asked to indicate the number of working males, working females, male students, female students and children whom are too young to be students with the results being provided in Table 1 . From the table, it was seen that the average number of males working within families was 1.58 males per family. A total of $68(18.48 \%)$ of the respondents indicated that there was no male working within their family while $169(45.92 \%)$ indicated that there was a single working male. Another 56 (15.22\%) indicated that there were two males working in their family unit while $40(10.87 \%)$ families contained three working males. The remaining numbers of working males can be seen in the table summarising the data.

In relation to working females, out of a total of 338 responses the largest return was seen in the area where one woman was working within the family which was indicated by $138(40.83 \%)$ respondents. This was closely followed by the option whereby there were no women employed within the family which was indicated by a

Table 1 . Family structure and working status

\begin{tabular}{|c|c|c|c|c|c|}
\hline \multirow{2}{*}{ No of individuals } & \multicolumn{2}{|c|}{ Working } & \multicolumn{2}{|c|}{ Students } & \multirow{2}{*}{ Under educational age } \\
\hline & Males & Females & Males & Females & \\
\hline 0 & $68(18.48 \%)$ & $137(40.53 \%)$ & $126(35.2 \%)$ & $127(35.77 \%)$ & $150(41.90 \%)$ \\
\hline 1 & $169(45.92 \%)$ & $138(40.83 \%)$ & $98(27.37 \%)$ & $104(29.30 \%)$ & $112(31.28 \%)$ \\
\hline 2 & $56(15.22 \%)$ & $37(10.95 \%)$ & $68(18.99 \%)$ & $69(19.44 \%)$ & $65(18.16 \%)$ \\
\hline 3 & $40(10.87 \%)$ & $11(3.25 \%)$ & $35(9.78 \%)$ & $26(7.32 \%)$ & $23(6.42 \%)$ \\
\hline 4 & $18(4.89 \%)$ & $11(3.25 \%)$ & $18(5.03 \%)$ & $15(4.23 \%)$ & $4(1.12 \%)$ \\
\hline 5 & $5(1.63 \%)$ & 0 & $5(1.4 \%)$ & $7(1.97 \%)$ & $1(0.28 \%)$ \\
\hline 6 & $7(1.90 \%)$ & $3(0.89 \%)$ & $3(0.84 \%)$ & $2(0.56 \%)$ & $2(0.56 \%)$ \\
\hline 7 & $2(0.54 \%)$ & $1(0.3 \%)$ & $1(0.28 \%)$ & $3(0.85 \%)$ & 0 \\
\hline 8 & $1(0.27 \%)$ & 0 & $2(0.56 \%)$ & $2(0.56 \%)$ & 0 \\
\hline 9 & $1(0.27 \%)$ & 0 & $2(0.56 \%)$ & 0 & 0 \\
\hline 10 & $1(0.27 \%)$ & 0 & 0 & 0 & 0 \\
\hline 14 & 0 & 0 & 0 & 0 & $1(0.28 \%)$ \\
\hline Total & 368 & 338 & 358 & 355 & 358 \\
\hline
\end{tabular}


total of 137 (40.53\%) of the respondents. The percentage of single working males or females in the family was not very different therefore. Overall, it seems that there are a slightly higher number of males in the labour forces than females.

In order to further assess the influence of the individuals' position within their family on their travel patterns a series of cross tabulations with other data sets was carried out. From the analysis, it was clear that travellers who finish working later are mainly men (AlAtawi, Saleh 2013).

\subsection{Work Sector}

Table 2 shows the distribution of respondents with social roles and place of work. From the table, one can see that females are mainly employed in the education sector compared with the average, no females in our sample work in Internal Affairs and Military and few females work in 'Health and Private'.

Table 3 shows the mode chosen cross tabulated results with the sector of work. From the data it can be seen that for all sectors driving is the most popular mode choice for all employment sectors with an overall rate of $53.6 \%$. The highest rate of driving being for an individual sector of jobs was seen with the Military of which $90.9 \%$ of respondents indicated that they drove. The educational sector, which had the highest response rate, was seen to have a percentage of drivers of $48.4 \%$ and about $43 \%$ use private, contract or informal drivers. This high percentage of drivers is likely to be due to the fact that such a high number of females are employed within this sector of whom very few drive. Al-Atawi and Saleh (2013) also show that the 'wife' has a higher average standard of education than the male members of the family as well as higher income which is an another important finding.

\subsection{Factors Affecting Mode Choice and Attitudes to Sustainability}

When respondents were asked to identify the factors, which affected the choice of mode, it was seen over all of the mode options available that comfort was the most common factor which influenced the individuals' choice. This was indicated by a total of $262(50.87 \%)$ of the individuals as being a determining factor in their decision making process. The next most influential factor was that of privacy which was indicated by 231 (44.9\%) of the respondents and was followed by cost effectiveness of the mode which was indicated by 209 (40.58\%). The fact that such a large proportion of respondents indi-

Table 2. Social role and place of work

\begin{tabular}{|c|c|c|c|c|c|c|c|c|c|}
\hline Social role & Education & Health & $\begin{array}{l}\text { Public } \\
\text { sector }\end{array}$ & $\begin{array}{l}\text { Internal } \\
\text { affairs }\end{array}$ & Military & $\begin{array}{c}\text { Private sector } \\
\text { (companies) }\end{array}$ & $\begin{array}{l}\text { Private sector } \\
\text { (other) }\end{array}$ & Other & Total \\
\hline Head & $68(41.7 \%)$ & $31(19.0 \%)$ & $34(20.9 \%)$ & $5(3.1 \%)$ & $10(6.1 \%)$ & $12(7.4 \%)$ & 0 & $3(1.8 \%)$ & 163 \\
\hline Wife & $62(74.7 \%)$ & $3(3.6 \%)$ & $11(13.3 \%)$ & 0 & 0 & $4(4.8 \%)$ & $2(2.4 \%)$ & $1(1.2 \%)$ & 83 \\
\hline Eldest son & $9(19.6 \%)$ & $4(8.7 \%)$ & $7(15.2 \%)$ & $3(6.5 \%)$ & $6(13.0 \%)$ & $13(28.3 \%)$ & $1(2.2 \%)$ & $3(6.5 \%)$ & 46 \\
\hline Daughter & $21(60.0 \%)$ & 0 & $7(20.0 \%)$ & 0 & 0 & $3(8.6 \%)$ & $2(5.7 \%)$ & $2(5.7 \%)$ & 35 \\
\hline Son & $15(35.7 \%)$ & $3(7.1 \%)$ & $10(23.8 \%)$ & $1(2.4 \%)$ & $2(4.8 \%)$ & $7(16.7 \%)$ & 0 & $4(9.5 \%)$ & 42 \\
\hline Other & $3(50.0 \%)$ & $1(16.7 \%)$ & $2(33.3 \%)$ & 0 & 0 & 0 & 0 & 0 & 6 \\
\hline Total & $178(47.5 \%)$ & $42(11.2 \%)$ & $71(18.9 \%)$ & $9(2.4 \%)$ & $18(4.8 \%)$ & $39(10.4 \%)$ & $5(1.3 \%)$ & $13(3.5 \%)$ & 375 \\
\hline
\end{tabular}

Table 3. Cross tabulation of mode chosen and sector of work

\begin{tabular}{lccccccccc}
\hline \multirow{2}{*}{ Transportation mode } & \multicolumn{7}{c}{ Sector of job } & & \\
\cline { 2 - 7 } & Education & Government & Health & Internal affairs & Military & Other & Private \\
\hline Bus & 3 & 0 & 1 & 0 & 0 & 0 & 1 & 7 \\
\hline Car sharing & 1 & 0 & 0 & 0 & 0 & 0 & 0 & 4 \\
\hline Cycling & 2 & 1 & 1 & 0 & 2 & 0 & 1 & 32 \\
\hline Drive & 90 & 46 & 40 & 10 & 17 & 10 & 34 & 279 \\
\hline Other & 0 & 0 & 0 & 0 & 0 & 0 & 0 & 1 \\
\hline Contract passenger & 24 & 5 & 2 & 0 & 0 & 1 & 2 & 35 \\
\hline $\begin{array}{l}\text { Informal passenger } \\
\text { share }\end{array}$ & 41 & 8 & 3 & 0 & 0 & 2 & 4 & 71 \\
\hline Private passenger & 14 & 7 & 1 & 0 & 0 & 0 & 3 & 28 \\
\hline Taxi & 0 & 0 & 0 & 0 & 0 & 0 & 0 \\
\hline Walk & 5 & 0 & 0 & 0 & 0 & 0 & 0 \\
\hline Total & 180 & 67 & 48 & 10 & 19 & 13 & 45 & 464 \\
\hline
\end{tabular}


cated cheapness as being a determining factor leads us to believe that they are not fully aware of all of the factors of each mode they take as in most instances the use of bicycles and walking are much cheaper than that of the private car. However, this desire to utilise the cheapest mode is not reflected in the actual mode choices as the private vehicles is by far the most commonly used mode. Environmental considerations was the factor which had the least influence on the mode choice of the survey group with only $66(12.8 \%)$ of the respondents indicating that it influenced their mode choice. Reliability was also a factor which was not deemed important by many individuals with $80(15.5 \%)$ responses in the category. $37(7.18 \%)$ individuals did indicate that other factors affected their mode choice.

Further investigations of the analysis show that the issues of peak congestion and air pollution are factors, which are of most concern to the individuals in relation to their impact on themselves and the general public. When we look at the general figures, it is seen that the respondents feel that others deem peak hour congestion and delays to be the major issues within the transportation network in Tabuk (Al-Atawi, Saleh 2013). Furthermore, respondents expressed strong support to policies, which aim at reducing congestion and improving environmental impact of the transport system as seen in Fig. 4.

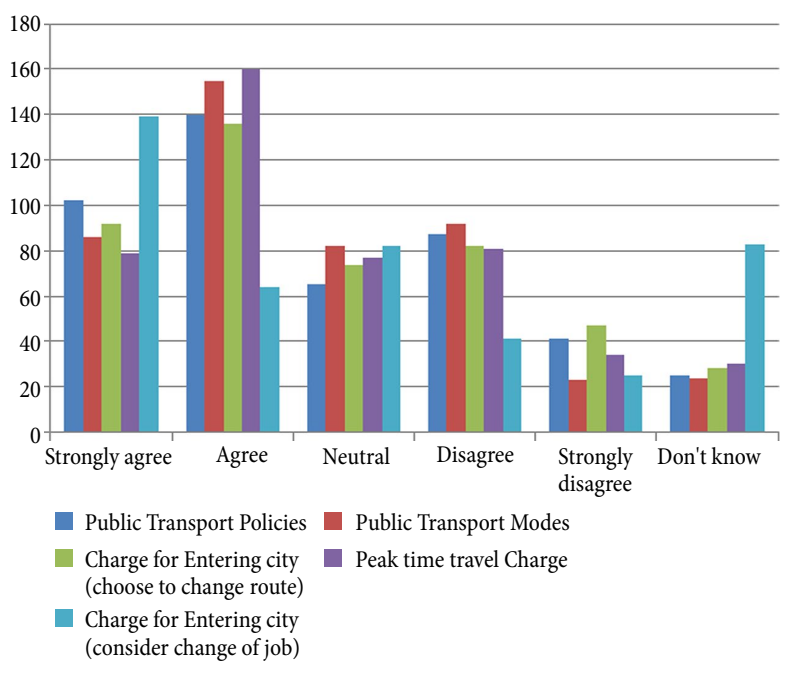

Fig. 4. Graph of findings in relation to respondents' acceptance of transport policy measures

\section{Discrete Choice Analysis}

In this section, discrete choice analysis and models have been calibrated and discussed for the main two modes of traveller behaviour as car user and car share, which are the private cars and informal car sharing. In Saudi cities, it is only male members of the family who are allowed to drive while female members use different modes of travel. In this analysis, two sets of models have been tested and discussed. The first model is a binary mixed logit model for male travellers who use the car and the factors, which affect the choice of the car as a mode of travel to work. The second model is also a binary mixed logit model for female travellers who use cars as passengers and they are labelled here as 'car sharers' and the factors which affect the choice of car sharing as a mode of travel are investigated and included in the model.

Because the outcome response of interest is dichotomous (i.e. using the car or not), an appropriate discrete-outcome model, given a set of prediction variables, is a binary mixed logit model, which is an extension of Random Utility Models (RUM). The mixed binary model is estimated using NLOGIT software (Econometric Software Inc. 2013) to evaluate the likelihood of 'using that mode' over 'not using the mode' have been investigated as functions of all the available traffic, individual and attitudes characteristics. A detailed derivation of this model has been, provided in several previous studies (e.g. Long 1997; Bhat 2003; Milton et al. 2008). In this case, a fairly standard set of linear in the parameters utility functions is utilised (Hensher et al. 2005).

While the main assumption of the logit model is that the constants and parameters of the models are represented by single parameters to represent all observations, the mixed logit model relaxes these assumptions and allow the use of randomly distributed parameters. The null hypothesis in this case is that $s d=0$, it can only be rejected if the $P$ values are lower than 5\% (for a 95\% level of confidence). The variables used in modelling are defined in Table 4 and modelling results are presented in Tables 5 and 6.

\section{Modelling Results}

Two binary mixed logit models were calibrated; one for each of the travel options 'MALE CAR_USER' and 'FEMALE INFORMAL CAR SHARING. Tables 5 and 6 present the results of the two models respectively. From Table 5 , it appears that social factors are the most effective and significant factors for the choice of mode of travel. The models show statistically significant coefficient estimates at $95 \%$ level of significance with logical signs for independent variables. As it can be seen from the results in terms of the position in the family, as expected the male family head is the most likely to be driving a car while the wife is the most unlikely to be driving a car (negative sign of the coefficient and zero probability). In terms of work sector, the results show that a male worker in private company, military and health sector are the most likely to be driving cars to work respectively with positive coefficients and probabilities of $0.0006,0.0033$ and 0.0039 respectively. The variable 'JOURNEY COST' is seen to be statistically significant at $95 \%$ level in the model and that it is uniformly distributed.

Table 6 presents 'FEMALE INFORMAL CAR SHARING' choice model. From the model it appears that the variables 'JOURNEY TIME', 'LEVEL OF EDUCATION' and the constant are statistically significant non random variables in the model. The variable 'ALTERNATIVE MODE (PASSENGER CONTRACTOR DRIVER)' is a negative, statistically significant random 
parameter, which is uniformly distributed in this model. This might imply that the contracted driver, if were available, might have been the preferred option to use for travelling. Further investigations in this area could also be useful and therefore recommended. Again, the social factors seem to be important and relevant in this case.
In summary, the models show statistically significant coefficient estimates at $95 \%$ level of significance with logical signs for independent variables. As It can be seen from the results in terms of the position in the family, as expected the male family head is the most likely to be driving a car while the wife is the most unlikely to be driving a car (negative sign of the coefficient).

Table 4. Description of variables selected for modelling

\begin{tabular}{|c|c|}
\hline Variable & Variable description \\
\hline Family member (HEAD) & $\begin{array}{l}\text { A dummy variable represents family structure and takes a value of } 1 \text { when the } \\
\text { family member is the 'Head' }\end{array}$ \\
\hline Family member (WIFE) & $\begin{array}{l}\text { A dummy variable represents family structure and takes a value of } 1 \text { when the } \\
\text { family member is the 'Wife' }\end{array}$ \\
\hline Place of Work (EDU) & $\begin{array}{l}\text { A dummy variable represents place of work and takes a value of } 1 \text { when the place } \\
\text { of work is 'Education Sector' }\end{array}$ \\
\hline Place of Work (HEALTH) & Place of work in health sector \\
\hline Place of Work (GOVT) & Place of work in government sector \\
\hline Place of Work (IAS) & Place of work in Internal Affairs and Security \\
\hline Place of Work (M) & Place of work in Military \\
\hline Place of Work (PC) & Place of work in Private Company \\
\hline Place of Work (OTH) & Place of work in other sector \\
\hline JOURNEY COST & A variable 'How often do you fill petrol in your car' to represent cost of travel \\
\hline LEVEL OF EDUCATION (LOW) & $\begin{array}{l}\text { A dummy variable represents level of education and takes a value of } 1 \text { when level } \\
\text { of education is 'Low' }\end{array}$ \\
\hline JOURNEY TIME & A variable represents reason of choosing the mode and 'Journey time' is chosen \\
\hline $\begin{array}{l}\text { ALTERNATIVE MODE (PASSENGER } \\
\text { CONTRACTOR DRIVER) }\end{array}$ & $\begin{array}{l}\text { Indicator variable of 'How would you make your journey to work if your current } \\
\text { mode (most regularly used mode) was not available to you?' with 'Passenger } \\
\text { Contractor Driver' option is selected }\end{array}$ \\
\hline
\end{tabular}

Table 5. Mixed logit model estimation results for 'MALE CAR_USER'

\begin{tabular}{lcccc}
\hline \multicolumn{1}{c}{ Variable } & Coefficient & Standard Error & $t$ value & $P$ value \\
\hline Non Random Parameters & & & & \\
\hline Constant & -1.6988 & 0.2962 & -5.7360 & 0.0000 \\
\hline Family member (HEAD) & 0.6784 & 0.3227 & 2.1020 & 0.0356 \\
\hline Family member (WIFE) & -2.1692 & 0.4739 & -4.5780 & 0.0000 \\
\hline Place of Work (EDU) & 0.6164 & 0.3731 & 1.6520 & 0.0985 \\
\hline Place of Work (HEALTH) & 1.5751 & 0.5452 & 2.8890 & 0.0039 \\
\hline Place of Work (GOVT) & 1.0002 & 0.4545 & 2.2010 & 0.0277 \\
\hline Place of Work (IAS) & 2.3930 & 1.2204 & 1.9610 & 0.0499 \\
\hline Place of Work (M) & 2.2133 & 0.7524 & 2.9420 & 0.0033 \\
\hline Place of Work (PC) & 1.8129 & 0.5316 & 3.4100 & 0.0006 \\
\hline Place of Work (OTH) & 1.5468 & 1.0039 & 1.5410 & 0.1234 \\
\hline Random Parameter & & & & \\
\hline JOURNEY COST & 0.5035 & 0.1092 & 4.6120 & 0.0000 \\
\hline Standard deviation of uniform distribution parameter & 0.5758 & 0.1659 & 3.4720 & 0.0005 \\
\hline Summary Statistics & & & &
\end{tabular}


Table 6. Mixed logit model estimation results for 'FEMALE INFORMAL CAR SHARING'

\begin{tabular}{|c|c|c|c|c|}
\hline Variable & Parameter Estimates & Standard Error & $t$ value & $P$ value \\
\hline \multicolumn{5}{|l|}{ Non Random Parameters } \\
\hline JOURNEY TIME & 0.096 & 0.027 & 3.585 & 0.0003 \\
\hline LEVEL OF EDUCATION (LOW) & 0.672 & 0.167 & 4.030 & 0.000 \\
\hline Constant & -5.978 & 1.020 & -5.860 & 0.0001 \\
\hline \multicolumn{5}{|l|}{ Random Parameters } \\
\hline ALTERNATIVE MODE (PASSENGER CONTRACTOR DRIVER) & -0.612 & 0.992 & -0.617 & 0.0537 \\
\hline Standard deviation of parameters & 3.082 & 1.523 & 2.023 & 0.043 \\
\hline \multicolumn{5}{|l|}{ Summary Statistics } \\
\hline \multicolumn{5}{|l|}{ Observations: 520} \\
\hline \multicolumn{5}{|l|}{ Restricted log-likelihood (constant only) $=-360.4365$} \\
\hline Log-likelihood at convergence $=-183.7058$ & & & & \\
\hline
\end{tabular}

In terms of work sectors, the results show that a male worker in private company, military and health sector are the most likely to be driving cars to work respectively. The variable 'JOURNEY COST' is seen to be statistically significant at $95 \%$ level in the model and that it is uniformly distributed.

\section{Conclusions and Recommendations}

This work demonstrates the importance of social factors when modelling traveller behaviour when travelling to work, in the context of work trips in the KSA. This importance is relevant in order to correctly determining the factors, which affect travel choices and decisions, and to be able to design and implement the most appropriate transport policies at the right locations and for the right users. Based on the calibrated results of mixed logit models it can be shown that for the male drivers to work, the social factors which include the position in the family, sector of work and travel costs represented by the inconvenience of how often the vehicle needed refuelling are the most important factors for the decision of driving a car. It is interesting however, to note that the cost of petrol has not been statistically significant in the models. This is of course because of the fact that petrol prices in Saudi Arabia are very cheap. For the female car sharers, travel time appears to have significance impacts on the decision of car sharing to travel to work, likely because of social commitments. In addition, level of education and unavailability of the alternative option (a contracted driver) have also been statistically significant variables in the models.

The results presented in this paper highlight the importance of the social factors in the decision making for the mode of travel for work trips in Saudi Arabia. It would be therefore appropriate in many cases to simplify the specifications of the models by using only those variables to represent the travellers' decisions since these are the most important factors here. Furthermore, in order to correctly plan for policies which aiming at influencing travel decision making, it is important to take into consideration the social factors of the decision makers. The factor by far more important is the role within the family. The head of family and the wife have extremely significant coefficients $(P<0.000)$ but opposite signs: Head $>0$, Wife $<0$. These mean that while the male members drive cars, the female members are usually travel sharing with other male members of the family.

The paper adds to the literature by contributing the investigation and findings from travel behaviour research in Saudi Arabia. The research identifies the importance of social factors on travel choice decisions in the country. The research also investigated awareness of respondents of issues related to sustainability and their willingness to alter their travel behaviour in order to improve the environment. These findings are applicable in a number of other similar countries in the region such as UAE, Qatar, Kuwait and Bahrain. The calibration of mixed logit models also allowed further investigations into the impact of contributory factors and the flexibility about the distribution of these factors. Further research into travel behaviour in the region is strongly recommended.

\section{Acknowledgements}

This research was funded by Tabuk University (Saudi Arabia).

\section{References}

Abdalla, I. M. 2002. Fatality risk assessment and modeling of drivers responsibility for causing traffic accidents in Dubai, Journal of Safety Research 33(4): 483-496. http://dx.doi.org/10.1016/S0022-4375(02)00052-X

Abou-Zeid, M.; Ben-Akiva, M. 2011. The effect of social comparisons on commute well-being, Transportation Research Part A: Policy and Practice 45(4): 345-361. http://dx.doi.org/10.1016/j.tra.2011.01.011

Adetunji, M. A. 2012. Gender travel behaviour and women mobility constraints in Ilesa, Nigeria, International Journal for Traffic and Transport Engineering 3(2): 220-229. http://dx.doi.org/10.7708/ijtte.2013.3(2).09 
Al-Atawi, A. M.; Saleh, W. 2013. Investigation and Modelling of Travel Behaviour in Saudi Arabia: a Disaggregate Approach. Final report. University of Tabuk, Saudi Arabia and Edinburgh Napier University, United Kingdom.

Al-Mohamed, A. 2008. Saudi women's rights: stuck at a red light, Arab Insight 2(1): 45-51.

Almunajjed, M. 1997. Women in Saudi Arabia Today. Palgrave Macmillan. 168 p. http://dx.doi.org/10.1057/9780230373105

Anable, J.; Gatersleben, B. 2005. All work and no play? The role of instrumental and affective factors in work and leisure journeys by different travel modes, Transportation Research Part A: Policy and Practice 39(2-3): 163-181. http://dx.doi.org/10.1016/j.tra.2004.09.008

Babatunde, I. R. 2012. Evaluating intra-urban transportation and gender travel behaviour in Ilorin, Nigeria, Global Journal of Human Social Science: Arts \& Humanities 12(14): 7-17.

Badoe, D. A.; Miller, E. J. 1998. An automatic segmentation procedure for studying variations in mode choice behaviour, Journal of Advanced Transportation 32(2): 190-215. http://dx.doi.org/10.1002/atr.5670320205

Bhat, C. R. 2003. Simulation estimation of mixed discrete choice models using randomized and scrambled Halton sequences, Transportation Research Part B: Methodological 37(9): 837-855.

http://dx.doi.org/10.1016/S0191-2615(02)00090-5

Cervero, R. 2002. Built environments and mode choice: toward a normative framework, Transportation Research Part D: Transport and Environment 7(4): 265-284. http://dx.doi.org/10.1016/S1361-9209(01)00024-4

Crane, R. 1998. Travel by design?, Access 12: 2-7.

Econometric Software Inc. 2013. NLOGIT is a Complete Econometrics and Statistics Package. Available from Internet: http://www.limdep.com/products/nlogit

Hensher, D. A.; Rose, J. M.; Greene, W. H. 2005. Applied Choice Analysis: a Primer. Cambridge University Press. 744 p.

Howarth, C. C.; Polyviou, P. 2012. Sustainable travel behaviour and the widespread impacts on the local economy, Local Economy 27(7): 764-781. http://dx.doi.org/10.1177/0269094212455149

Koushki, P. A. 1988. The effect of socio-economic development on household travel behavior in Saudi Arabia, Socio-Economic Planning Sciences 22(3): 131-136. http://dx.doi.org/10.1016/0038-0121(88)90014-6

Limtanakool, N.; Dijst, M.; Schwanen, T. 2006. The influence of socioeconomic characteristics, land use and travel time considerations on mode choice for medium- and longerdistance trips, Journal of Transport Geography 14(5): 327341. http://dx.doi.org/10.1016/j.jtrangeo.2005.06.004

Long, J. S. 1997. Regression Models for Categorical and Limited Dependent Variables. SAGE Publications, Inc. 328 p.

Milton, J. C.; Shankar, V. N.; Mannering, F. L. 2008. Highway accident severities and the mixed logit model: an exploratory empirical analysis, Accident Analysis \& Prevention 40(1): 260-266. http://dx.doi.org/10.1016/j.aap.2007.06.006

Mohammadian, A. 2005. Gender differences in automobile choice behavior, in Research on Women's Issues in Transportation. Report of a Conference. Volume 2: Technical Papers, 41-48.

Mohareb, N. I. 2010. Land use as a sustainability indicator for Arab cities, Proceedings of the ICE - Urban Design and Planning 163(3): 105-116.

http://dx.doi.org/10.1680/udap.2010.163.3.105
Paul, B. K.; Rimmawi, H. S. 1992. Tourism in Saudi Arabia: Asir National Park, Annals of Tourism Research 19(3): 501-515. http://dx.doi.org/10.1016/0160-7383(92)90133-A

Saleh, W.; Sammer, G. 2009. Travel Demand Management and Road User Pricing: Success, Failure and Feasibility. Ashgate Publishing. 268 p.

Shokoohi, R.; Hanif, N. R.; Dali, M. 2012. Influence of the socio-economic factors on children's school travel, Procedia - Social and Behavioral Sciences 50: 135-147. http://dx.doi.org/10.1016/j.sbspro.2012.08.022

Srinivasan, S. 2002. Quantifying spatial characteristics of cities, Urban Studies 39(11): 2005-2028. http://dx.doi.org/10.1080/0042098022000011335

Srinivasan, S.; Rogers, P. 2005. Travel behavior of low-income residents: studying two contrasting locations in the city of Chennai, India, Journal of Transport Geography 13(3): 265-274. http://dx.doi.org/10.1016/j.jtrangeo.2004.07.008

Yang, L.; Zheng, G.; Zhu, X. 2013. Cross-nested logit model for the joint choice of residential location, travel mode, and departure time, Habitat International 38: 157-166. http://dx.doi.org/10.1016/j.habitatint.2012.06.002 